\title{
14
}

\section{A IMPLEMENTAÇÃO DA PEDAGOGIA HISTÓRICO-CRÍTICA: FORMAS, EXIGÊNCIAS E DESAFIOS ${ }^{* 1}$}

Paulino José Orso²

\section{Introdução}

Como o próprio nome indica, este capítulo trata das formas, exigências e desafios da implementação da Pedagogia Histórico-Crítica, que se constitui numa teoria pedagógica transformadora, cuja suas primeiras elaborações ocorreram no final da década de 1970, mais precisamente, em 1979, e, em 2021, completa 42 anos de história. Inicialmente vou situar o local de onde falamos, passarei pela discussão em torno de questões conceituais, discutirei sobre a necessidade de superar alguns equívocos e reducionismos, abordarei as formas de institucionalização, as condições e exigências para sua implementação e, por fim, tratarei da importância e necessidade de empreender um plano para difundi-la e torná-la conhecida em todo o país.

\section{Questões preliminares: de onde falamos}

Ao iniciar nossa discussão, é importante destacar que nos encontramos em 2020, portanto, distante 42 anos do momento em que foram feitas as primeiras elaborações textuais acerca da Pedagogia

*DOI - 10.29388/978-65-86678-91-8-0-f.287-314

${ }^{1}$ Este capítulo é resultado da aula ministrada no dia 10 de dezembro de 2021, na disciplina Pedagogia Histórico-Crítica e prática transformadora, oferecida pela Faculdade de Educação da Unicamp, coordenada pelo professor José Claudinei Lombardi. A mesma foi organizada e ministrada de foram coletiva, envolvendo 22 professores de diferentes instituições do país, realizada por via remota, articulando seis programas de pós-graduação e mais de cinco mil extensionistas espalhados por todo o país.

${ }^{2}$ Doutor em História e Filosofia da Educação pela Unicamp, professor dos cursos de Pedagogia, do mestrado e doutorado em Educação da Universidade Estadual do Oeste do Paraná Unioeste, líder do Grupo de Pesquisa em História, Sociedade e Educação no Brasil - GT da Região Oeste do Paraná - HISTEDOPR. E-mail: paulinorso@uol.com.br. 
Histórico-Crítica (PHC) (1979), pelo professor Dermeval Saviani, percurso esse, do qual, já podemos extrair muitas lições e aprendizagens.

Como nenhuma teoria pedagógica surge do nada, pode-se afirmar que seu surgimento também deve ser entendido, simultaneamente, como produto de um contexto de crise política, econômica, social e educacional, e resposta a essa sociedade e à realidade que a suscitou. Como tal, revelase como uma exigência social, a exigência de uma nova educação, comprometida com a superação das condições existentes e a construção de uma nova sociedade.

Ao longo de sua trajetória, porém, a PHC já capitalizou uma importante produção teórica, muitos estudos, pesquisas, eventos e reflexões. Além disso, acumula diversas experiências de institucionalização. Contudo, é necessário destacar que, por dois motivos, não se constitui numa espécie de "pacote" pronto e acabado para "colocar em prática". Primeiro porque se trata de uma teoria educacional em construção, uma construção coletiva, que envolve muitos educadores e pesquisadores. Segundo, porque não se constitui numa fórmula ou numa receita a ser aplicada em todo e qualquer contexto. Daí a necessidade de aprofundar estudos, pesquisas, desfazer equívocos e ampliar as discussões para que possamos aperfeiçoá-la, compreendê-la melhor e formar uma grande orquestra, cada vez mais afinada.

Além do mais, como se trata de uma teoria pedagógica transformadora, e não de uma teoria ou prática pedagógica qualquer, "isenta" e descompromissada, supõe tanto uma mudança da mentalidade educativa quanto da prática pedagógica, de modo que realmente seja transformadora. Isso supõe aprender em que consiste e como realizar uma prática efetivamente transformadora. Contudo, como a prática pedagógica é um ato intencional e planejado, carece de reflexão e trabalho para que se possa antecipar no plano mental e textual a prática pedagógica transformadora. Por isso, de um lado, discorremos sobre a prática pedagógica, e de outro, sobre a institucionalização, que, aliás, tem sido objeto de poucos estudos, pesquisas e discussões.

\section{Questões conceituais}

Começamos por esclarecer a diferença entre implementação e institucionalização. Elas não são sinônimas. Uma coisa é a implementação e outra a institucionalização. No que diz respeito à educação escolar, a 
implementação corresponde à realização prática da teoria por meio da prática pedagógica. E a institucionalização, diz respeito à sua adoção por parte de um município, de um estado, pelo distrito federal, e até mesmo, pela União, e sua transformação na proposta pedagógica oficial, com o objetivo de arregimentar as condições para viabilizar a implementação da PHC em toda sua rede de abrangência.

Assim, como a implementação e a institucionalização não se confundem, também não dependem uma da outra. Uma coisa é a prática pedagógica e outra a institucionalização. Mas, não só podem como deveriam se constituir numa unidade e andar juntas.

Da relação entre elas podem resultar três posições. Uma, em que determinados docentes adotam a PHC como sua teoria pedagógica mesmo sem que tenha sido institucionalizada. Outra, em que, apesar de sua institucionalização, em vez de se pautarem pela proposta oficial, determinados docentes continuam trabalhando da forma como lhes convém, guiados pela sua experiência, pelos seus hábitos, costumes e tradições. E uma terceira posição ocorre quando há a unidade entre institucionalização e prática pedagógica, quando a prática pedagógica dos docentes corresponde à proposta pedagógica oficial.

É desnecessário dizer que, tanto a adoção da PHC por parte dos docentes como sua institucionalização, em última instância, devem ter em vista a realização do ensino e da aprendizagem de acordo com esta teoria.

Entretanto, alguns perguntam, por que ou para que discutir sobre implementação? Por que discutir sobre institucionalização? Não seria melhor debater acerca das questões teóricas, sobre seus pressupostos, seus fundamentos, seus conteúdos, sobre o currículo, a didática, o método, enfim, sobre a relação teoria $X$ prática?

Diria que tratar das questões teórico-metodológicas sem se preocupar com a sua implementação, é o mesmo que ficar divagando. A teoria carece da prática, fica oca e vazia sem ela. Falar da implementação é teorizar sobre a prática, é discutir sobre as formas e condições para transformar a imaginação, o sonho, a teoria em realidade; é revolucionar, é dar uma nova forma à matéria; é transitar para outro lugar sem sair de onde se está. Ou seja, é mais ou menos o mesmo que produzir uma obra de arte, é pegar a matéria, negar sua forma atual e dar-lhe uma nova forma.

Enfim, a implementação é o encontro da teoria com a prática e da prática com a teoria. Tanto a teoria quanto a prática existente são 
superadas, deixam de ser o que eram/são em si mesmas, e dão lugar a uma nova realidade, a uma nova materialidade, a uma nova práxis.

Quando Saviani versa sobre os cinco passos da PHC, em sua obra seminal Escola e democracia, ao tratar da catarse, que considera como sendo o ponto culminante do processo de ensino e aprendizagem, citando Gramsci, afirma que é o momento da "elaboração superior de estrutura em superestrutura na consciência dos homens". (GRAMSCl, citado por Saviani, 1983, p. 75).

Pois bem, muitos chegam na catarse, ou então, à superestrutura, e param aí, no "conforto" de uma nova interpretação da educação, de uma compreensão histórico-crítica. Outros, nem sequer chegam até aí, limitamse a citar Saviani e repetir trechos de obras que se ocupam da PHC. Diferente disso, chegada à catarse, é hora de transitar para "outro lugar", e imprimir uma nova forma à matéria, à realidade, à sociedade, ao mundo.

Se a catarse implica na elaboração da estrutura em superestrutura na consciência dos homens, como a PHC se constitui numa teoria pedagógica transformadora, por mais elaborada e sistematizada que seja, não pode parar na superestrutura, isto é, na elaboração da estrutura na consciência humana. Este é apenas um momento do processo. Se fizermos isso, transformaremos a PHC numa espécie de enfeite cerebral.

Diferente disso, não se constitui em apenas uma nova interpretação da educação. Trata-se sim de uma nova interpretação que, uma vez elaborada, se quisermos que realmente seja transformadora, como diria Marx (1818-1883), é hora de "descer do céu à terra", para então sim, "subir da terra aos céus". Quer dizer, é hora de agir, de traduzir e transformar a teoria em uma nova prática, produzir uma nova materialidade e imprimir uma nova forma à realidade existente.

O conhecimento crítico não se esgota em si mesmo, no ato de conhecer. As ideias, ainda que importantes, têm seu limite, carecem da força material, pressupõem, necessária e concomitantemente, a ação transformadora. Como nos dizem Marx e Engels, (2003, p. 137), "Para execução das ideias são necessários homens que ponham em ação uma força prática".

A implementação, portanto, é a hora da prática, é a hora de, com base no novo conhecimento elaborado, produzir uma nova prática social. Dizendo de outro modo, é a hora de transformar a superestrutura numa espécie de guia ou de instrumento de ação e transformação da estrutura existente numa nova estrutura social, numa nova sociedade. 
Pesquisar, estudar e discutir acerca da Pedagogia Histórico-Crítica sem se preocupar com sua realização prática, sem pensar na sua materialização e implementação, como dissemos, é o mesmo que transformá-la numa espécie de enfeite, num adorno cerebral, ou em apenas mais uma teoria pedagogia ou numa pedagogia qualquer, despreocupada, descompromissada e descomprometida. Porém, isso não condiz com a PHC. Afinal, ela não se constitui num fim em si, objetiva a transformação social.

Diria que a implementação da PHC é mais ou menos como a cereja do bolo. Sim, pensem numa festa. Não fica sem graça o bolo de uma festa sem a cereja? Mas, a cereja é a "última coisa" que se coloca. Antes é necessário satisfazer uma série de condições e exigências. Afinal, não é possível colocá-la sobre o vazio, sobre o nada. Traduzindo, significa que não há possibilidade de prática sem teoria, isto é, não dá para se implementar algo sem que se saiba o que, como, de que forma e com que meios se faz isso.

A implementação, ou se quiserem, a prática pedagógica, é, portanto, a razão de ser da teoria. É mais ou menos como o gran finale, a apoteose, a finalização perfeita, para a qual concorrem todos os preparativos para que fique irretocável.

Ainda que, como veremos adiante, a expressão "colocar em prática", frequentemente utilizada em relação à $\mathrm{PHC}$, seja imprecisa, neste momento vou me utilizar dela para dizer que ninguém coloca em prática o nada. A "prática pedagógica" demanda de uma série de preparativos teóricos e práticos. Sem teoria resta apenas uma ação qualquer, como dissemos, cega, oca e vazia.

Por conseguinte, a implementação, ou se quiserem, a prática, além de se constituir num ponto de chegada, também expressa, representa e simboliza o elo de unidade em que, simultaneamente, articula-se o passado, isto é, a apropriação teórico-metodológica, a formação do educador, e o futuro, uma nova educação, um novo homem, uma nova sociedade.

Partindo do pressuposto de que a pedagogia histórico-crítica é uma teoria pedagógica revolucionária e transformadora, o momento da implementação, consequentemente, transforma-se no critério de verdade. A prática revela o educador, demonstra até que ponto se apropriou adequadamente da teoria, se age em conformidade com ela, e, por conseguinte, até que ponto está ou não sendo revolucionário. Depreende- 
se, portanto, que o conhecimento da PHC é condição sine qua non à sua implementação. Sem conhecimento da teoria, não há prática revolucionária possível.

Também, não adianta estudarmos, discutirmos e pesquisarmos sobre os pressupostos, a didática, a metodologia, enfim, sobre todos os elementos que a caracterizam, e, na hora da implementação e institucionalização, desconsiderarmos e agirmos de qualquer modo, com base nas experiências, nos hábitos e nos costumes passados, ainda que não devamos desconsiderá-los. Quer dizer, não podemos fazer de conta que uma coisa é a teoria e outra a prática, ou, que na prática a teoria é outra.

Ao contrário, a institucionalização e a implementação devem ser entendidas como o "espelho", a expressão e a representação da teoria. Por conseguinte, considerando-se que a pedagogia histórico-crítica se constitui numa teoria revolucionária, a sua institucionalização e implementação devem se revelar como um ato e uma prática revolucionária.

Nada obstante, para que a prática pedagógica seja revolucionária, também é necessário superar alguns equívocos e mal-entendidos. Vejamos alguns deles.

\section{Superação de reducionismos, equívocos e mal-entendidos}

Ao tratar da pedagogia histórico-crítica e sua implementação, é comum ouvirmos as seguintes indagações: "Como é que se coloca em prática a $\mathrm{PHC}^{\prime}$ ? A quem ela se destina? Pode-se trabalhar com ela só nos cursos de pedagogia ou em todas as áreas e em todos os níveis do conhecimento? Dá para trabalhar só com adultos ou também com crianças? É uma teoria pedagógica para a educação escolar ou serve de referencial para o trabalho educativo em todo e qualquer espaço educativo?

\subsection{A PHC e a relação teoria e prática}

Como se pode perceber, as questões remetem para uma determinada compreensão de pedagogia histórico-crítica. E, como dissemos, entendê-la adequadamente, é uma condição necessária para uma prática efetiva. Afinal, somos bastante coerentes, tal como pensamos, agimos. Não pensamos ou falamos de um determinado modo e agimos de outro, de modo contrário. A não ser que tenhamos algum problema mental. Mas se for este o caso, é preciso buscar o auxílio de especialistas. 
Primeiramente, é forçoso esclarecer que a PHC não se confunde com algo pronto, com uma espécie de fórmula ou de uma receita a ser posta em prática, nem com um carimbo a ser reproduzido de igual forma em todos os lugares. Não se trata de "abrir uma gaveta" e de retirar uma fórmula ideal e "colocá-la em prática".

\subsection{Superar reducionismos}

Outro equívoco, é reduzir a PHC a um ou a outro aspecto ou elemento do processo de ensino e aprendizagem. Ela não se reduz nem aos procedimentos metodológicos, à didática, aos pressupostos teóricometodológicos, à psicologia do desenvolvimento humano e da aprendizagem, à transmissão e socialização dos conteúdos, a uma nova forma de gestão da educação, a um novo currículo, a uma nova teoria educacional, a uma prática pedagógica e, nem mesmo, a um método. Contudo, não dispensa nenhum destes componentes.

Então, se não se reduz a nenhum deles, e, simultaneamente, pressupõe a todos, em que consiste a PHC? Consiste numa concepção de educação, ou se quiser, numa teoria pedagógica que envolve a totalidade do processo de ensino e aprendizagem e considera as múltiplas determinações. Mas, também não se limita a isso, pois, qualquer teoria pedagógica pode contemplar esses mesmos elementos.

\subsection{Diferença entre a PHC e as demais teorias e ou práticas pedagógicas}

Então, onde está a diferença entre a PHC e as demais teorias e ou práticas pedagógicas? A diferença é que ela não é apenas mais uma teoria pedagógica ou uma pedagogia qualquer. Ela possui uma teleologia, está voltada para uma finalidade, para a transformação social, objetiva o desenvolvimento omnilateral de todos os agentes envolvidos, a emancipação humana.

Portanto, o que diferencia a PHC das demais teorias pedagógicas é o fato de que ela assume um compromisso explícito com a transformação social. Diria que seu acento principal não está nem em seus pressupostos, na socialização dos conhecimentos, na psicologia da aprendizagem, na metodologia, na didática etc., tanto enfatizados, e sim, no seu caráter revolucionário e transformador, na construção de uma nova educação, um novo homem, uma nova sociedade e uma nova humanidade. Assim, articula 
todos os seus componentes numa concepção e numa práxis pedagógica transformadora. Do contrário seria apenas mais uma teoria pedagógica qualquer.

Não há dúvida de que todos esses elementos são indispensáveis. Mas, por mais relevantes que sejam, nenhum deles é suficiente ou tem uma finalidade em si. Ao invés disso, pressupõe socializar conteúdos, adotar uma didática e uma metodologia, considerar as etapas de desenvolvimento, enfim, ensinar com a finalidade de transformar, tendo em vista propiciar as condições para o pleno desenvolvimento humano e social. Por conta disso, não basta trabalhar qualquer coisa, ensinar qualquer conteúdo, de qualquer modo, de forma despretensiosa e descompromissada.

\subsection{O caráter histórico-crítico da PHC}

Outra questão relevante diz respeito à historicidade. Aliás, não é por acaso que a PHC se chama pedagogia histórico-crítica. Contudo, não raras vezes, vemo-la praticamente sendo reduzida à historicização dos objetos ou dos conteúdos. Contudo, ainda que, tanto a história quanto a crítica sejam intrínsecas a ela, também não se limita nem a uma nem a outra.

É necessário considerar que muitos escritos de Saviani são datados. Por exemplo, quando trata da questão da materialidade da ação pedagógica, alerta para três grandes problemas educacionais: a descontinuidade, a ausência de um sistema educacional, e a necessidade de, ao se adotar uma nova teoria pedagógica, articular os instrumentos, os meios e a prática, à nova teoria e não continuar agindo em conformidade com as teorias do passado (SAVIANI, 2011, p. 92).

Vejamos o caso da descontinuidade. Saviani está correto ao afirmar que a descontinuidade é um grande problema para a educação, uma vez que esta pressupõe a ininterrupção das ações por um tempo suficiente até que se tornem irreversíveis.

Pense, porém, na tragédia que será, por exemplo, se, ao invés da descontinuidade, tivermos a continuidade das políticas educacionais dos governos Temer e Bolsonaro. Logo, impõe-se tanto a necessidade da derrota do governo Bolsonaro, quanto a ruptura, ou então, a descontinuidade em relação às atuais políticas educacionais.

Mas, não se trata da defesa da continuidade nem da descontinuidade em si. Defender uma ou outra em si e de per si, poderia acarretar a ne- 
gação a priori das contradições de classes e, consequentemente, uma compreensão estática e abstrata da realidade.

A questão da continuidade ou descontinuidade são próprias da sociedade dividida em classes. Expressam as lutas inerentes à divisão social. Não as admitir seria o mesmo que negar a materialidade e desconsiderar que a sociedade é permeada por classes e por lutas de classes e, portanto, por lutas e disputas de interesses, teorias e projetos. Logo, se as desconsiderarmos, negaremos a própria $\mathrm{PHC}$ que tem como pressuposto a materialidade histórico-social, e a transformaremos em mais uma teoria pedagógica ou em uma teoria pedagógica qualquer. Portanto, é necessário considerar a realidade tal como é, nos inserir na luta, disputarmos espaços e projetos, e superarmos essa sociedade em que impera a descontinuidade.

Algo assemelhado ocorre com o problema da ausência de um sistema educacional. É claro que a ausência de um sistema educacional acarreta uma série de problemas para a educação. Todavia, sua criação, por si só, também não resolve o problema educacional. Se pensarmos que a BNCC (Base Nacional Comum Curricular) define um conjunto de aprendizagens essenciais que os alunos devem desenvolver ao longo de todas as etapas da Educação, em todo o território nacional, pode se dizer que agora temos um sistema, ao menos para a Educação Infantil e para o Ensino Fundamental. Contudo, ele não só não representa a solução do problema educacional, como o agrava e expressa seu inverso, o desmonte de um mínimo de qualidade.

Essas questões têm sido difundidas à exaustão, porém, de forma abstrata, irrefletida e a-histórica. Ou seja, para trabalhar na perspectiva da PHC, não basta reproduzir o que Saviani escreveu. É preciso contextualizar e, sobretudo, não esquecer que a sociedade é de classe, que implica em lutas e disputas.

Por outro lado, no caso da afirmação de que a PHC se constitui numa teoria crítica e contra hegemônica, alguns interpretam como se fosse sinônimo de ser do contra, ou então, que é preciso criticar tudo. Não, não se trata disso. Ser contra hegemônica significa assumir uma posição ou proposta oposta à dominante, que anda na contramão daquilo que é dominante, contrário à reprodução do status quo.

Ser revolucionário, por exemplo, significa ser contra hegemônico. $\mathrm{E}$ ser crítica significa que a teoria não parte do mundo das ideias, daquilo que as pessoas pensam, imaginam ou gostariam, do que simpatizam ou antipatizam, mas sim, da base real, da produção e reprodução da vida 
social, das condições existentes, da forma de funcionamento da sociedade, das relações existentes, enfim, da realidade objetiva.

\subsection{A PHC enquanto teoria pedagógica contra hegemônica}

A PHC surge como uma pedagogia contra hegemônica e, até o momento, encontra-se nessa condição, compondo o conjunto das pedagogias contra hegemônicas. Contudo, se ela se insere no campo das pedagogias contra hegemônicas, são poucas as que, além disso, também se constituem em teorias pedagógicas contra hegemônicas.

A PHC, porém, não se satisfaz em ser contra hegemônica, almeja se tornar hegemônica. Até mesmo as teorias ou práticas que hoje são dominantes, nem sempre o foram, nem permanecerão como tal. A pedagogia histórico-crítica, por sua vez, objetiva ser conhecida, agir por entre as contradições, travar a luta contra as atuais condições socioeducativas, ser apropriada e defendida pela maioria dos educadores, sair da "marginalidade" e passar à condição de teoria dominante e hegemônica.

\subsection{A PHC e a transformação social}

Outra questão problemática, que é bastante comum entre educadores, é a que se refere à relação entre educação e transformação. Frequentemente ouvimos: "a educação não transforma a realidade"; "a educação sozinha não transforma a sociedade"; no máximo, a educação opera a "transformação das consciências", ou ainda, "a transformação não virá de dentro das academias".

Não consigo entender por que alguns educadores incorporaram esse discurso e essa prática senão "negacionista", no mínimo minimalista e até mesmo reprodutivista.

Ora, se falarmos que a educação não transforma, por que haveríamos de nos empenhar em construir uma teoria pedagógica transformadora? Pergunto: Com base em que se chegou a essas conclusões? Do fato de que a escola está situada na sociedade capitalista? Não foi essa a razão do surgimento da PHC, da existência da exploração e da dominação, e, consequentemente, da necessidade de sua superação? Ou teria surgido da constatação de que as academias são burocratizadas? De que há muitas lutas e disputas no interior das escolas e universidades? 
De que a educação não consegue transformar tudo sozinha? Se a educação e as academias não transformam, quem transformará? Os sindicatos? Os partidos? Os movimentos sociais populares? Contudo, esses espaços não são burocratizados? Neles, não ocorrem problemas? Farão eles a revolução sozinhos?

Diante disso, alguns dizem, o que está em questão é que a educação não transforma sozinha. Então, pode-se afirmar que, junto, a educação, os partidos, os sindicatos, os movimentos sociais etc., transformam?

Contudo, se não há unidade interna nas diferentes categorias, as lideranças e os profissionais da educação, dos partidos, dos sindicatos e dos movimentos populares irão se unir por "um motivo mais nobre", por uma causa superior, a revolução e a transformação social? Na prática ocorre esta unidade? Creio que não é necessário responder. Quer dizer, incorremos na mesma problemática. Parece que repetimos refrões e chavões de forma irrefletida e abstrata, e os transformamos numa espécie de dogmas, de verdades inquestionáveis.

Ora, se afirmarmos que a educação não transforma, não transforma, nem vamos nos empenhar em transformar, não é mesmo? Ou, pensamos de um determinado modo, isto é, falamos que a educação não transforma, e agimos de modo contrário, ou seja, adotamos uma prática transformadora? É óbvio que não. Assim como é óbvio que a educação não se constitui na totalidade social. Se fosse essa a exigência para ser revolucionária, nem a educação, nem ninguém transformaria, retornaríamos ao naturalismo.

O fato de não poder tudo, de não ser absoluta, autônoma e independente, não impede que a educação seja revolucionária. Ou melhor, não impede que sejamos revolucionários. Na medida em que adotarmos práticas articuladas e coerentes com uma teoria revolucionária, a educação pode sim ser revolucionária, pode sim ser transformadora. Do contrário não será. Nós podemos ser ou não ser revolucionários. Depende de nós..., depende de como pensamos e agimos, depende de nossa prática. Ainda que, é claro, não depende apenas e exclusivamente de nossa vontade individual.

Por outro lado, afirmar que a educação não transforma as condições materiais e a estrutura social porque "trabalha com ideias", e que se limita à "transformação das consciências" (OLIVEIRA, 1994, p. 118), é o mesmo que admitir que a escola, independentemente da materialidade, 
pode "colocar" um conjunto de alunos em uma sala de aula, "doutriná-los" e "produzir consciências". Nesse caso, poderíamos transformar a escola numa espécie de "forma", numa "fábrica" de consciências, e, conforme a necessidade, "produzi-las".

Contudo, pergunto: O que seria a consciência, uma "iluminação", um "estado" de conhecimento? É possível "chegar na consciência" e parar nela? A educação começaria na consciência e pararia nela? Pensar desse modo não seria equivalente ao platonismo ou ao hegelianismo? É possível pensar em uma "consciência" isolada da prática? Se as ideias, de acordo com a concepção materialista, são a expressão da materialidade, que muda conforme muda a realidade, é possível pensar numa consciência isolada do mundo? Não. O ser consciente é o ser consciente do mundo, cuja prática corresponde ao seu pensamento. Logo, a consciência não está dissociada da prática. No caso da pedagogia histórico-crítica ela se revela como práxis transformadora.

Não se trata aqui da questão se a educação e os educadores podem ou não transformar a sociedade sozinhos, nem se a totalidade da educação será ou não revolucionária, se todos os educadores serão ou não revolucionários, se ela ou eles podem transformar toda a realidade.

Afinal, nada nem ninguém está sozinho nem isolado no mundo. Ademais, a história se constitui na síntese das múltiplas vontades, interesses, lutas e disputas que se travam no conjunto da sociedade. Portanto, atribuir a transformação social ao indivíduo ou à escola isoladamente, seria o mesmo que negar seu caráter social e sua materialidade efetiva. Além disso, a grande Revolução não se resume a um ato, nem se transforma tudo de uma só vez. A revolução se constitui num movimento, num processo. Consequentemente, os educadores, suas ações e suas práticas podem revolucionar ou não a realidade existente. Depende do que e como fazem sua prática.

\subsection{Será a PHC uma teoria pedagógica para o futuro?}

Tendo presente que a socialização das máximas produções, o desenvolvimento omnilateral e a emancipação humana preconizados pela pedagogia histórico-crítica, só se efetivarão plenamente com a superação da sociedade de classes e do capitalismo, muitos têm interpretado que a PHC só será viável no futuro, após a revolução, em outra sociedade, póscapitalista. 
Ora, isso também não condiz com a PHC. Entender desse modo, seria o mesmo que pressupor que é algo pronto, estático e acabado, é negar seu caráter materialista histórico e dialético, é negar seu caráter revolucionário e transformador. Seria o mesmo que esperar que a revolução "aconteça", para depois pegar o "pacote teórico" já pronto e "colocar em prática".

Não, a história não dá saltos. Por isso, há que se fazer a revolução aqui e agora, todos os dias e todas as horas... Para isso a necessidade de uma pedagogia guiada por uma teoria que atue sobre a realidade e a transforme. Consequentemente, nossa prática pedagógica e nossos atos devem ser revolucionários. Devemos agir de tal modo que vamos somando e acumulando forças, superando as atuais relações, até chegarmos à grande Revolução, à transformação radical e profunda da sociedade, e criarmos as condições para, então sim, viabilizar a plena realização dos ideais defendidos pela PHC. Contudo, também não se trata de etapismo. Se não for possível se fazer o máximo, façamos o possível, no limite das condições e possibilidades existentes onde nos encontramos, em cada momento, mas façamos.

A pedagogia histórico-crítica se constitui numa teoria pedagógica que opera na e com a materialidade, que atua nas e com as contradições, nos e com os antagonismos de classes, tendo em vista sua superação.

Se não fosse assim, não só não seria necessária, como seria inútil. Sim, pois, se fosse uma teoria pedagógica para o futuro, simplesmente não haveria necessidade de criá-la no passado nem agora, deveríamos esperar para criá-la após a revolução. Porém, se não fizermos nada aqui e agora, se continuarmos a repetir que "a educação não transforma a realidade", se nos limitarmos a reproduzir, a revolução não ocorrerá. Logo, não necessitaremos de uma teoria revolucionária.

Como a superação do capitalismo e, portanto, a produção do futuro não cairá do céu, nem virá por si só, sem muito trabalho e luta, precisamos de uma teoria revolucionária, como é o caso da PHC, que opera na materialidade, que corresponde à própria realidade, e promova uma prática pedagógica revolucionária. Contudo, se nossa vida não for expressão de luta e da revolução cotidianamente, não será na escola que iremos nos travestir, agir de modo diferente e ser revolucionários.

Portanto, a PHC é uma teoria educacional que veio para ficar. É para antes, durante e depois da grande Revolução. Como produto da 
sociedade de classes, quanto mais age e nega essa sociedade, mais se realiza, mais se completa, mais se valoriza e se enriquece enquanto teoria.

Como mencionamos, o centro da pedagogia histórico-crítica e sua especificidade se encontra em seu caráter revolucionário e transformador. Aliás, mesmo que provisoriamente, pedagogia revolucionária foi o primeiro nome que Saviani atribuiu a ela.

A pedagogia por mim denominada ao longo deste texto", afirma Saviani, "na falta de uma expressão mais adequada, de 'pedagogia revolucionária', não é outra coisa senão aquela pedagogia empenhada decididamente em colocar a educação a serviço da referida transformação das relações de produção. (SAVIANI, 1982, p. 63; 1983, p. 79; 2011, p. 118).

Contudo, como se encontrava nos "anos de chumbo", de ditatura, caso fosse mantido tal nome, é bem provável que seria abortada logo em seu nascedouro.

Portanto, a questão que se coloca é, como, quando e em que condições a educação pode ser revolucionária e ou os educadores podem agir de tal modo que sejam revolucionários? Diria que, se bem entendido, agir em consonância como a PHC se constitui num ato revolucionário. Adiante veremos, porém, as exigências e condições para que isso aconteça.

Falamos anteriormente que a expressão "colocar a PHC em prática" é imprecisa. Diferente disso, trata-se de trabalhar de acordo, na perspectiva, em consonância com sua concepção político-pedagógica.

Dizendo de outro modo, a primeira condição para que a educação seja revolucionária é a existência de uma teoria pedagógica revolucionária. Afinal, como afirma o educador russo Moisey Mikhaylovich Pistrak (18881940) (2018, p. 32), “[...] sem teoria pedagógica revolucionária, não poderá haver prática pedagógica revolucionária”.

Mas, também não é suficiente termos uma teoria revolucionária. Afinal, como diria Vladimir llyich Ulianov, mais conhecido por seu codinome Lênin (1870-1924), "uma teoria sem prática de nada vale e uma prática sem teoria é cega". Uma implica na outra. Do contrário, no máximo a que se pode chegar é ao verbalismo, à catarse ou ao ativismo. Uma educação revolucionária, portanto, implica tanto uma teoria quanto uma prática pedagógica revolucionária. Ou então, na medida em que os indivíduos transformam a estrutura em superestrutura, é hora de fazer desta um guia 
para ação e transformação social. Teoria e prática se pressupõem e devem se encontrar e se revelar como uma práxis revolucionária.

Assim, desfeito esses mal-entendidos, passamos às formas de institucionalização.

\section{Formas de institucionalização da Pedagogia Histórico-Crítica}

Como dissemos, a implementação e a institucionalização da PHC não são a mesma coisa. Lembremos que a institucionalização da PHC é a adoção dessa teoria pedagógica por parte de um determinado ente federativo, por um município, um estado, pelo distrito federal ou pela própria União, e sua transformação na proposta pedagógica oficial para toda sua rede de abrangência.

Então, quais são as formas ou os caminhos que temos para institucionalizar? Existem basicamente duas formas. Uma, ocorre a partir da mobilização, da luta e das exigências da base, dos docentes, como foi o caso do estado do Paraná e do município de Itaipulândia. Outra, que ocorre por iniciativa dos gestores, das secretarias ou departamentos de educação, conforme o caso, e das equipes pedagógicas, como aconteceu em Limeira, e, de certo modo, também em Cascavel e Bauru, ainda que já existissem algumas discussões e ações assistemáticas acerca da PHC.

Todavia, qual é a melhor forma de proceder para se institucionalizar? Qual delas é mais relevante, mais consistente, mais sólida, mais resistente e tende a ser mais duradoura? Há uma forma que seja mais importante ou elas se equivalem?

Diria que são diferentes formas de se realizar a institucionalização. A primeira, inicia-se pela base, pelos estudos, pelas leituras individuais, pelas discussões por parte dos docentes, que vão ganhando corpo, conquistando adesões e ampliando o número de pessoas comprometidas com a proposta, até granjear forças e se transformar em um movimento, numa exigência dos profissionais da educação, de tal modo que a institucionalização se revela como expressão da vontade majoritária dos envolvidos e não reste alternativa ao executivo senão adotá-la e transformá-la na proposta pedagógica oficial.

No caso da segunda forma, ocorre de modo inverso. Principia pela iniciativa do poder executivo (do/a secretário/a e ou equipe pedagógica) e 
depois se espraia pela base ${ }^{3}$. Mas, como não parte da escolha e da opção dos docentes da base, necessita fazer um esforço e um trabalho maior e mais intenso de persuasão e convencimento dos profissionais da educação sobre a relevância e necessidade de sua adoção e implementação.

Ainda que a primeira forma seja resultado da iniciativa da base, como a sociedade não é monolítica, mesmo assim ocorrerem resistências. Em função disso, após sua institucionalização, a despeito de ter sido uma demanda de grande parte dos profissionais da rede, exige um intenso trabalho de sensibilização e convencimento dos demais professores no sentido de também aderirem e assumirem a nova proposta.

Por outro lado, se a iniciativa partir do oficialato, é provável que a resistência seja maior, por não ter sido uma exigência da base e não contar com sua adesão imediata. Assim, possivelmente necessitará de um trabalho mais intenso para quebrar resistências e convencer o conjunto dos docentes a aderirem à proposta.

Contudo, como se trata de institucionalizar para poder implementar uma teoria contra hegemônica, uma pedagógica revolucionária, numa sociedade de classes, na sociedade capitalista, certamente ocorrerá resistências dentro e fora da escola, independentemente de onde ou de quem partir a iniciativa de institucionalizar, se da base ou dos gestores. Daí a necessidade de pensar em estratégias para contornar a situação de tal modo que não comprometa a proposta.

Como aludimos, a primeira forma tende a ser mais sólida, mais consistente e duradoura, uma vez que é resultado da iniciativa de uma parcela significativa dos docentes. Assim, se ocorrer a mudança de gestão ou da equipe pedagógica, por exemplo, tende a resistir e se manter, uma vez que foi assumida pela base. Daí a importância de se investir no trabalho de formação e "conquista dos corações e mentes" do maior número possivel de educadores.

No caso da segunda forma, é um pouco mais frágil, pois, além da normal resistência que pode ocorrer por parte de determinados docentes e de elementos da comunidade externa, caso o/s responsável/is pela iniciativa seja/m removido/s, representará um duro golpe ao processo.

Todavia, como no primeiro caso, a institucionalização é uma exigência dos profissionais da educação, e no segundo, os docentes

\footnotetext{
${ }^{3}$ Há que se destacar que, mesmo que a iniciativa da institucionalização tenha partido dos gestores, alguns docentes da base já tinham conhecimento e realizavam leituras e discussões em torno da PHC.
} 
precisam ser convencidos de sua importância e necessidade, significa que se deve optar somente pela primeira forma?

O ideal seria que fosse realizada por meio de processos democráticos, com discussão, mobilização, consulta e comprometimento dos envolvidos. Entretanto, a opção ou adoção de uma ou outra modalidade de institucionalização depende das condições de cada momento, em cada local. De qualquer modo, seja numa ou noutra modalidade, ela não se resume a um ato, envolve um processo.

Isso significa que não basta formalizar a proposta, ou seja, fazer com que seja transformada em oficial. No primeiro caso, a institucionalização é apenas mais um passo, mais um momento do processo. No segundo, constitui-se apenas no primeiro passo. A partir daí iniciam-se as ações e o planejamento para transformar a proposta oficializada até que se realize efetivamente na prática pedagógica cotidiana da escola, por todos os educadores.

O processo de institucionalização e implementação, por sua vez, também não se confunde com um conjunto de ações feitas a esmo. Ao contrário, exige organização, planejamento, definição de um plano de trabalho, com objetivos, estratégias, passos, meios, condições, metas e avaliação.

Entretanto, depois das experiências de institucionalização já realizadas, dados os entraves burocráticos e, por vezes, a resistência dos docentes e as pressões externas, considerando que vivemos numa sociedade capitalista, que o estado é burguês e não cria e nem oferece as condições para viabilizá-la, e, muito menos, para realizar a omnilateralidade e a emancipação humana, alguns se perguntam: Vale a pena investir na institucionalização da pedagogia histórico-crítica?

Faço aqui duas observações. Uma é que, de fato vivemos na sociedade capitalista e que o estado é burguês e, sendo a PHC uma pedagogia contra hegemônica, é óbvio que não propiciará as condições para implementá-la, pois, trata-se de uma proposta contrária aos interesses dominantes, que, em geral, controlam o estado.

Seria ingenuidade esperar que o estado burguês colocasse todos os meios à disposição para lutar contra si próprio. Desconsiderar isso, significaria o mesmo que acreditar que a classe dominante aceita qualquer tipo de educação ou pensar que ela não se preocupa com educação. Contudo, basta ver o Movimento "Todos pela Educação", o "Escola 'sem' Partido", as discussões em torno da tal "ideologia de gênero", e os ataques 
aos educadores e às ciências humanas, dentre outros, para perceber que a burguesia não só está muito interessada, como não aceita qualquer um tipo ou um projeto de educação.

Portanto, considerar que a sociedade é de classe e, consequentemente, de luta, não é só uma questão primordial, como é indispensável à pedagogia histórico-crítica. Inclusive, é uma de suas razões de ser. Afinal, se a sociedade não fosse de classe, a PHC nem sequer teria sido criada.

A despeito destas ponderações ou em função delas, diria que a PHC deve ter na institucionalização uma de suas metas, pois, trata-se de viabilizar as condições para tornar acessível a todos, de forma igual e indistintamente, os bens culturais e os bens materiais mais desenvolvidos produzidos ao longo da história, pelo conjunto dos homens.

Não obstante, tendo presente que a implementação da PHC não se limita ao ato em si de institucionalizar, como a sociedade é dividida e de classe e, portanto, como ela (PHC) não se constitui numa unanimidade, como envolve luta e resistência, tanto a institucionalização quanto a implementação pressupõem avaliação permanente do processo para acompanhar, verificar se as metas estão ou não sendo atingidas e, se necessário, redefinir estratégias, promover mudanças e corrigir rumos.

Portanto, a definição quanto a melhor forma de se institucionalizar e implementar a PHC deve ser avaliada e decidida em cada momento e local. Contudo, faz-se necessário satisfazer algumas condições e exigências básicas, como veremos na sequência.

\section{Condições e exigências para a implementação da Pedagogia Histórico-Crítica ${ }^{4}$}

Considerando que, como dissemos, a PHC se constitui numa teoria pedagógica contra hegemônica, revolucionária e transformadora, quais são as condições e exigências para implementá-la?

\footnotetext{
${ }^{4}$ Sobre essa temática sugiro a leitura de meu artigo Pedagogia Histórico-Crítica no Campo, publicado na coletânea intitulada Pedagogia histórico-crítica e educação no campo: história, desafios e perspectivas atuais, organizada por Jaqueline Daniela Basso, José Leite dos Santos Neto e Maria Cristina dos Santos Bezerra, publicada em São Carlos, por Pedro \& João Editores e editora navegando, 2016, p. 105-111. O mesmo pode ser acessado neste endereço: http://www.gepec.ufscar.br/publicacoes/livros-e-colecoes/livros-gepec/pedagogia-historicocritica-e-educacao-no-campo.pdf
} 
Primeiramente, é necessário dizer que, se for bem entendida, podese trabalhar com ela em todas as áreas do conhecimento, em todos os níveis de escolaridade, em todas as modalidades e em todos os espaços educativos. Pois, trata-se de uma teoria pedagógica e, portanto, de uma concepção que abarca a educação na sua totalidade. No entanto, como dissemos, ninguém trabalha de acordo com a perspectiva da PHC se não a conhece. O domínio da teoria é condição básica e indispensável para se trabalhar com ela.

Porém, como alguns não compreendem adequadamente a concepção que lhe é inerente e a reduzem a um ou alguns elementos que a compõem, não conseguem entender e ensinar determinados conteúdos, nem trabalhar em determinadas áreas do conhecimento ou em determinados espaços educativos em consonância com ela. Entretanto perguntam: "Como colocar em prática?"

O fato é que, não existe didática, método, metodologia ou qualquer artifício que dê conta de trabalhar de acordo com o que preconiza a PHC se não se entender apropriadamente sua teoria e os fins a que se propõe. $O$ domínio da teoria é uma exigência primeira. As demais exigências decorrem dela.

Do mesmo modo, não é possível dar conta de se trabalhar com ela, se não dominar os conteúdos. Está claro que a realização de um trabalho educativo voltado para a transformação estrutural da sociedade, que possibilite transitar para uma sociedade socialista e comunista, tal como defende a Pedagogia Histórico-Crítica, exige domínio dos conteúdos.

Ademais, é necessário dominar os conteúdos para poder trabalhálos de acordo com uma teoria pedagógica, pois, não se ensina, nem se ensina de determinada forma ou de acordo com uma determinada perspectiva, o que não se conhece. Logo, é necessário dominar os conhecimentos mais elaborados existentes nas diversas áreas caso se queira socializá-los.

Contudo, ao discutir sobre o trabalho pedagógico nas disciplinas escolares, há que se se ter cuidado para não reforçar a divisão e a fragmentação do saber, pensando que, para se trabalhar de acordo com a PHC, basta trabalhar os conteúdos de uma disciplina, de uma determinada forma, mantendo e reproduzindo o conhecimento como se fosse um conjunto de gavetas disciplinares estanques e incomunicáveis.

O domínio da teoria e dos conteúdos, porém, ainda que necessários, indispensáveis e imperativos, não são suficientes para se 
trabalhar com a PHC. Também é imprescindível dominar o método materialista histórico-dialético, que é adotado por ela, pois, é o único que permite compreender efetivamente a realidade, suas contradições, sua dinâmica, os antagonismos sociais, e se inserir como agente transformador. Portanto, sem dominar o método não há possibilidade de se trabalhar com a PHC.

Há que se ressaltar, todavia, que, se o conhecimento do método materialista é indispensável à PHC, trabalhar de acordo com sua concepção não é sinônimo nem se reduz a falar ou fazer uma defesa de princípio do método, como se observa em muitos casos. O mesmo se pode falar em relação aos chamados "cinco passos" ou os "cinco momentos" da PHC. Ou então, no intuito de criticar uma determinada apropriação do método, representá-lo de modo diferente, mesmo que seja com uma terminologia marxista. Mais do que isso é necessário que a prática pedagógica "espelhe", expresse e represente o método e os "cinco passos" ou "momentos".

Outra exigência imperiosa é conhecer o funcionamento da sociedade. Mas, como se pode concluir pelo exposto, não se trata de qualquer conhecimento, afinal, todo mundo conhece. Em primeiro lugar, porque, em se tratando de educação escolar, cabe à escola propiciar um conhecimento de tipo específico, sistematizado, científico, que não é oportunizado pela mídia, na família, no trabalho, na igreja, nem nas interações cotidianas. Em segundo lugar, porque, como se trata de transformar a sociedade existente, pressupõe um conhecimento que ultrapasse o nível do imediato, do empírico, do fenomênico, da aparência, e permita compreender efetivamente a realidade, que implica dominar as leis de seu funcionamento, a etapa de desenvolvimento do capital e conquistar a consciência de classe.

Afinal, ainda que o conhecimento não seja suficiente para transformar a realidade, como está direta e indiretamente relacionado às interações e demandas sociais, um conhecimento pobre, em geral, também se associa e se conforma com demandas pobres e elementares, jamais se coaduna a uma práxis transformadora. Se não se conhece a sociedade e o mundo na radicalidade, é provável que não só não se sinta a necessidade ou não se queira transformar, como é até possível que se oponha à transformação. Além do mais, se não se conhece para além das aparências, vamos transformar o quê, em quê, para quê, para quem, quando, como?

Portanto, caso queiramos promover uma prática educativa que, mais do que lançar um outro olhar sobre o mundo ou interpretá-lo de outra 
maneira, que permita intervir efetivamente e transformá-lo, é necessário conhecer sua forma de organização, sua dinâmica, seu funcionamento e acompanhar o desenvolvimento das contradições e das lutas, tanto em âmbito local e como global.

Também é necessário um projeto de educação transformadora. Ter um projeto é saber onde se está e aonde se quer chegar. Se não se quiser sair de onde se está, isto é, se não se tiver um projeto, se não se souber aonde se quer chegar, certamente não se irá a lugar algum, se estará à mercê das circunstâncias. Por conseguinte, não há possibilidade de se atuar de acordo com a PHC se o espontaneísmo for o guia, se não se tiver um projeto claro, consciente, crítico, planejado e sistemático de educação articulado ao projeto de sociedade que se quer construir. Consequentemente, é necessário arquitetar um novo projeto de educação para outro tipo de sociedade conforme defende a PHC.

Por fim, como a transformação geral e profunda não ocorrerá fortuitamente, como "as armas da crítica não são suficientes", nem resultará de um acordo ao redor de uma mesa de negociações, ou se quiserem, da "conciliação entre as classes", não dá para trabalhar na perspectiva da PHC, sem as adequadas "críticas das armas", se não se tiver determinação e compromisso com a revolução.

Em síntese, para se trabalhar na perspectiva da PHC, é preciso dominar sua teoria pedagógica, os conteúdos, o método materialista histórico-dialético, conhecer profundamente o funcionamento da sociedade, construir um projeto revolucionário de educação e realizar uma prática pedagógica transformadora.

Mas, do mesmo modo que entendemos que a prática pedagógica é um ato intencional, planejado e consciente, como o conhecimento da teoria pedagógica é uma condição básica para sua implementação e institucionalização, faz-se necessário traçar um plano para difundi-la e torná-la conhecida. Afinal, ainda que o indivíduo seja importante, sozinho de nada vale.

\section{Operação Cavalo de Tróia}

Não podemos esquecer, como já enfatizamos, que nos encontramos numa sociedade de classes, e que a PHC é uma teoria contra hegemônica. Isso significa que tanto sua institucionalização como sua implementação não ocorrerão de forma natural e espontânea. E muito menos sem que as pessoas a conheçam. Sem que seja conhecida, 
apropriada e defendida não há possibilidade de institucionalização nem de implementação.

Por outro lado, se ela for conhecida, e entendida como uma teoria que corresponde aos interesses da classe trabalhadora, isto é, aos nossos interesses, aos interesses da imensa maioria da população, não resta dúvida de que, caso os profissionais da educação se compreenderem como integrantes dessa classe, não há dúvida de que a adotarão como sua teoria pedagógica. Só não a abraçarão caso não a compreenderem ou não se reconhecerem como membros da classe trabalhadora.

Ademais, a consciência social é objeto de disputa. A classe dominante detém muitos meios políticos, ideológicos, burocráticos e repressivos, tanto para tentar impedir e/ou camuflar a consciência de classe dos trabalhadores, como, se for o caso, para conter os que dela se apropriam.

Por isso, é imperativo arquitetar um plano, definir estratégias, traçar objetivos e metas, tanto no sentido de difundi-la, como para torná-la conhecida pelos educadores, uma vez que se constitui numa exigência elementar para sua implementação. E, como atuamos na contra hegemonia e a disseminação da PHC não ocorre naturalmente, necessitamos definir táticas, uma espécie de operação "Cavalo de Tróia" para "plantá-la" no seio da sociedade.

Da mesma forma que entendemos que o trabalho pedagógico é um ato intencional, voluntário e planejado, a difusão da PHC e sua transformação numa teoria dominante, hegemônica, pressupõe um plano. Afinal, é necessário difundi-la massivamente e defendê-la, de tal modo que assim como ocorreu no estado do Paraná, em 1990, num dado momento, gostem os governos ou não, não reste alternativa a eles, senão adotá-la e transformá-la na teoria pedagógica oficial, uma vez que terá se tornado expressão da vontade da maioria dos educadores.

Com esta finalidade, por exemplo, depois de muitos ensaios e experiências, após analisar e refletir sobre a história da pedagogia históricocrítica e as atividades desenvolvidas pelo HISTEDBR e pelo HISTEDOPR, concluímos que, caso quiséssemos realmente implementar e institucionalizar a PHC e transformá-la numa teoria hegemônica, capaz de revolucionar toda a realidade, primeiramente, deveríamos realizar uma tarefa básica e simples, qual seja, difundi-la e torná-la conhecida.

Com essa motivação, no segundo semestre de 2016, decidimos realizar um trabalho com o objetivo de reunir educadores e promover um 
conjunto de estudos sistemáticos e continuados em torno da Pedagogia Histórico-Crítica. Assim, no primeiro semestre de 2017, realizamos a primeira etapa dos grupos de estudos da pedagogia histórico-crítica.

Eles são resultados de muitas atividades realizadas desde 2002, quando o HISTEDOPR foi criado, abrangendo vários grupos de estudos sobre temáticas diversas, atividades de pesquisa e extensão, ciclos de debates, cursos de especialização etc.

O objetivo dos grupos é reunir pessoas, promover estudos e discussões em torno da PHC, ampliar sua difusão por todo o país e, se possível, para além dele. Inicialmente, as atividades eram semestrais. Principiamos com um grupo de 27 pessoas, estudando a obra Pedagogia Histórico-Crítica: primeiras aproximações, de autoria de Dermeval Saviani, e concluímos com 21.

Ao final dessa etapa, lançamos o desafio de que, ao mesmo tempo em que elas continuariam os estudos com a obra Escola e Democracia, outra obra seminal da PHC, cada uma organizasse um grupo em sua escola ou em seu município. Assim, ao final de 2017, não chegamos somente a 21 grupos, criamos 50 grupos, a maioria dos quais nas regiões Oeste e Sudoeste do Paraná. Mas, realizamos um grande feito. Por meio de um exaluno do curso de mestrado da Unioeste (André das Chagas Santos), organizamos um grupo em Santarém-PR. Nesse momento, percebemos que era possível sair do âmbito local, regional e do estado do Paraná, e atingir todo Brasil.

Com isso nos animamos. Mas, como fazer isso? A estratégia foi transformar as atividades em anuais, e, com o apoio da Pró-Reitoria de Extensão e do Setor de Informática da Unioeste, adaptar a plataforma de eventos para a realização dessa atividade. Dessa forma, tornou-se possível organizar grupos em qualquer escola, município, estado, e em todo e qualquer lugar, até mesmo, em outros países. Assim, em 2018, propomonos um novo desafio, criar 100 grupos. Muitos consideravam algo impossível.

Mas, com muito trabalho, em vez de 100 grupos, como que tínhamos estabelecido como meta, chegamos a mais que o dobro, atingimos 223 grupos, envolvendo 3.056 pessoas, de 17 estados.

Não resta dúvida de que organizar 223 grupos de estudo era uma grande façanha. Mas, pensávamos, o que representam 223 grupos, envolvendo pouco mais de 3 mil pessoas!? Para se verificar, de um lado, a relevância e, de outro, a "insignificância" que representava, basta observar 
que o estado do Paraná tem 399 municípios e não havíamos sequer chegado ao equivalente a um grupo por município. E tínhamos o Brasil e o mundo por conquistar. Como chegar lá?

Então, com tantos grupos, com os contatos que cada um poderia fazer com os colegas, amigos e conhecidos em suas escolas, em outros municípios e estados, ampliamos a aposta, propusemo-nos como meta para 2019, chegar a 500 grupos.

Mas, "a história não é linear" (ORSO, 2014, p. 169). Para nossa surpresa, em vez de aumentar, o número de grupos diminuiu. Ficamos em 168 grupos, em 13 estados, envolvendo 2.359 pessoas. Mesmo assim, era motivo de comemoração, pois tratava-se de 169 grupos. Se fossem apenas 169 pessoas estudando a PHC já era algo importante. Mas, ao invés disso, eram 169 grupos.

Depois, preparamos as atividades para 2020 (https://www5.unioeste.br/portalunioeste/phc-2020/objetivos) e chegou a Covid-19. Como os encontros eram presenciais, para evitar riscos à saúde, adiamos o início e nos somamos à disciplina ofertada pelo professor José Claudinei Lombardi (Zezo) sobre a "PHC e prática transformadora", pela Unicamp, junto à qual ministramos esta aula sobre a institucionalização da $\mathrm{PHC}$, chegando a mais de cinco mil participantes.

Em 2021, apesar da covid-19 não dar tréguas, como a pandemia estimulou as atividades remotas, retomamos os encontros, com a quinta etapa dos grupos de estudo.

Diante do contexto do golpe de 2016 e do cenário catastrófico que se acenava a partir daí, sentíamos a necessidade urgente de difundir a PHC. Mas, como fazer isso, se muitas pessoas não a conheciam? Pensávamos que, se tivéssemos que estar presentes em cada grupo e local para falar dela ou sobre ela, não conseguiríamos dar conta de mais que dois ou três grupos. Daí a ideia de organizá-los na modalidade de autogestão, isto é, de forma que todos pudessem organizar um grupo ou participar de algum deles, independentemente do nível de conhecimento que tinham/têm dela e de trabalhar na educação básica ou superior, pública ou privada, de ser aluno ou professor.

A forma de funcionamento dos grupos é muito simples. Estabelecemos um programa de estudos e os interessados em organizar um grupo reúnem colegas, nos encaminham um e-mail (cascavel.grupodeestudosphc@unioeste.br) com seus dados pessoais e sua localização. Aí, criamos o grupo e comunicamos para que os demais integrantes se cadastrem 
nele. Não tem um número mínimo nem máximo de membros. Sugerimos, porém, que seja entre 5 e 30 pessoas para possibilitar melhor aproveitamento das discussões. Contudo, já tivemos grupos com 60 pessoas.

São 8 encontros em cada etapa. Cada grupo conta com um coordenador e um relator, que ficam responsáveis pelo controle de frequência, por dinamizar as discussões, registro das principais questões e dúvidas que ocorrem em cada encontro. Esse relato é lido no início do encontro seguinte e, ao final de cada etapa anual, é feito um relatório, que é transformado em Anais, e publicado na plataforma do grupo, podendo ser registrado no Currículo Lattes como um trabalho apresentado em evento. Os coordenadores recebem certificado pela Unioeste de 50 horas e os demais participantes com 40 horas.

Traçamos uma programação para vários anos, que vai desde a discussão dos fundamentos da PHC, passando pelo método até chegar às questões relativas à institucionalização e à implementação. O objetivo é fazer uma caminhada articulada e conjunta, e atingir todo o país, com todos os grupos discutindo as mesmas questões.

$\mathrm{Na}$ medida em que se reúnem, enquanto leem, discutem e se apropriam da teoria, também debatem sobre questões relativas à escola, ao bairro, à cidade, à política, à economia, à sociedade, ao Brasil e ao mundo. Assim, os grupos se transformam em grandes espaços de discussão político-pedagógicos.

Esperamos, portanto, contar com sua participação tanto na organização e ou na participação nos grupos, como na divulgação e ajuda para organizar novos grupos, atingir locais onde ainda não chegamos. Organize um grupo você também! Veja se na escola próxima, ou no seu ou em outro município ou estado tem alguém que conheça e que pode fazer o mesmo. Ajude a chegar em todos os recantos do seu município, do estado e do país. Desse modo, nos tornamos um grande coletivo sintonizado numa mesma direção; desse modo, a PHC deixará de ser uma pedagogia contra hegemônica e passará a ser hegemônica.

Mas, como diria Eduardo Galeano, "o barco não anda se não tiver água". Quero dizer que encontramos muita dificuldade na disponibilização de material para os estudos. Além disso, nos deparamos com a questão dos direitos autorais e, no caso desse projeto, não basta qualquer texto que fale da PHC, necessitamos de produções articuladas ao projeto. Por isso, solicitamos empenho tanto na produção quanto na socialização de conteúdos. Caso contrário, "o barco não anda por falta de água". 
Os grupos de estudos, todavia, são apenas uma das formas de difundir e tornar a PHC conhecida. Para transformar a pedagogia históricocrítica numa teoria pedagógica hegemônica e podermos realizar em plenitude os ideais preconizados por ela, precisamos de muitas outras iniciativas, tais como, a discussão em sala de aula, a oferta de disciplinas sobre a PHC nos cursos de graduação e nos programas de pós-graduação, a realização de lives e eventos, a organização de cursos e projetos de extensão, dentre muitas outras, que cada um/a está convidado a promover. "Juntos podemos mais, juntos podemos fazer melhor".

Por fim, gostaria de dizer que, ainda que a adoção da pedagogia histórico-crítica por uns e outros seja importante, somente conseguiremos implementá-la efetivamente e subsistir, se for entendida e assumida como um compromisso coletivo, seja em relação à sua construção, à produção de material, à socialização das produções e sua difusão, seja em relação à sua institucionalização e sua implementação. A construção de uma nova humanidade, fim último da pedagogia histórico-crítica, demanda de muitos esforços, de muitas iniciativas e de muitas mãos.

A causa vale a luta!

\section{Referências}

MARX, Karl; ENGELS, Friedrich. A sagrada família. São Paulo: Boitempo, 2003.

PISTRAK, Moisey Mikhailovich. Fundamentos da escola do trabalho. São Paulo: Expressão Popular, 2018.

ORSO, Paulino José. A classe trabalhadora, a consciência de classe e a educação. Uma história que não é linear. In.: ORSO, p. j., GONÇALVES, S. R. e MATTOS, Valci. Sociedade capitalista, educação e as lutas dos trabalhadores. São Paulo: 2008.

SAVIANI, Dermeval. Escola e Democracia: para além da "teoria da curvatura da vara". In.: Revista ANDE, 1982. Disponível em:

file://C:/Users/Paulino/Downloads/Texto\%20Escola\%20e\%20democracia \%20(1).pdf. Com acesso em 01.12.2020.

SAVIANI, Dermeval. Escola e Democracia. São Paulo: Autores Associados e Cortez Editora, 1983. 
SAVIANI, Dermeval. Pedagogia Histórico-Crítica: primeiras aproximações.

Campinas: Autores Associados, 2011. 